\title{
How to Maintain Sustainable Competitive Advantages-----Case Study on the Evolution of Organizational Strategic Management
}

\author{
Ning He \\ School of Economics and management, Xi' an University of Post \& Telecoms \\ 536 South of Chang'An Road, Xi'an 710061, China \\ E-mail: hening915@126.com
}

Received: July 21, 2012

doi:10.5430/ijba.v3n5p45

\author{
Accepted: August 4, $2012 \quad$ Online Published: September 12, 2012 \\ URL: http://dx.doi.org/10.5430/ijba.v3n5p45
}

\begin{abstract}
The aim of the article is to analyze why the sustainable competitive advantage may disappear for many business organizations, and how to maintain the advantages in order to survive in the market. The paper proposes an evolution path of strategic literature, from the classical Porter's strategic theory to business inertia, strategic resilience, then Organizational transformation, finally to the Business sustainability. Based on the case studies and literature review, this paper makes a conclusion that competitive advantages of organizations have a life cycle which starts from a planned selection and subsequent resource accumulation, however, enduring success requires sustainable competitive advantages and implies continuous improvement and innovation. This paper is empirically explored in many explorative, historical case studies to research the evolution path of firm's strategic planning processes. The author aims at helping the firm leaders to solve complicated, uncertain management issues arising from today's dynamic business areas.
\end{abstract}

Keywords: Business resilience, Competitive advantage, Organization transformation, Business sustainability

\section{Introduction}

Based on the case studies and literature review, this paper makes a conclusion that competitive advantages of organizations have a life cycle which starts from a planned selection and subsequent resource accumulation. But when resources are changing with a high evolutionary rate or market dynamism is very turbulent in the life cycle, the temporary competitive advantage can not maintain. Usually, the temporary competitive advantages will be replicated by the competitors and in order to make the resources and related competitive advantages become sustainable, these competitive advantages must be redeployed in other product markets. Regarding the competitive advantage life cycles, the various stages of resource evolution should be the crux of research. The resources which are key to competitive advantages should be renewed, replicated, redeployed, or recombined to enhance growth and market share in a highly uncertain business world. This paper is empirically explored in many explorative, historical case studies to research the evolution path of firm's strategic planning processes.

The first half of this paper is to explore the initial competitive advantage of firms, then to analyze the reason why the earlier advantage will disappear. Based on the resilience, organization transformation theory, and business sustainability view, the lower half of the article is to research on how to maintain the completive advantage for firms. Concerning methodology, note that this paper does not follow a standard research approach (empirical modeling), but builds on insights from existing literatures. Opinions were collected from the media and other primary sources. The ABI/Inform database was widely used. With regard to the contribution of this thesis, the article aims at contributing to the theoretical and practical policy discussions in two ways. At a conceptual level, it proposes an evolution path of strategic literature, from the classical Porter's strategic theory to current popular views of organization sustainability. At a practical level, the article aims at helping the firm leaders to solve complicated, uncertain management issues arising from today's dynamic business areas.

\section{Sources of Competitive Advantage --- A Classical View}

Organizational competitiveness has become the center in the strategic management literature as an explanation for organizations' success. A landmark author in this field is Porter who explicitly introduced concepts of competitive strategy, competitive forces and competitive advantage. (Christopher Heywood, Russell Kenley, 2008)Among tons of 
strategic literatures, one typical inside perspective is that an organization's internal environment - resources, capabilities, value-adding services in a value chain- are used to account for its core competencies of the organization.

\subsection{Low Cost ---- To Provide an Efficiency}

According to Porter's classical model, cost and differentiation are two initial sources of competitive advantages. Low-Cost strategy is based on overall cost leadership with efficiency, tight-cost control (Porter, 1985). For example, Wal-Mart's high profitability is a result of lower cost of advertising, flat organizational structure, superior information systems and logistics, and efficient use of capital. Besides that, Southwest Airlines is one of the standout companies in the U.S. airline industry. The secret of its success relies mainly on the low-cost strategy. For instance, Southwest Airlines flies only point-to-point lines, it has a reputation for fewer delays, flies only one type of plane, reduces training costs, maintenance costs, and inventory costs, provides no meals, no movies in flight, and does not transfer baggage to other airlines. These operations make Southwest Airlines becomes very successful even in the crisis of U.S. airline industry after 911.

\subsection{Differentiation ---- To Make a Difference}

Differentiation, as a source of advantage, means offering unique brand, technology, customer service and products to gain the market share (Porter, 1985). In Spain, the famous fashion retailer Zara is one of the country's fastest growing and most successful companies. The basis for the success is the company's speed in designing and merchandising the products in stores. In this turbulent fashion industry, compared with other firms, Zara's products can reach the stores in only five weeks, as opposed to nine months of other fashion companies, this fast respond to market is achieved through Differentiation strategy in design, information systems and logistics management. Zara has its own factories, designers and stores. Significantly, their designers are in close contact with the stores and can respond very quickly to the changing trends. Moreover, The Company purchases basic textiles from global suppliers but performs the final production activities in its own facilities using computer controlled machinery to cut the fabric. In conclusion, this Spanish fashion retailer Zara make a difference by reacting faster than the competitors. This case illustrates how Zara has built a competitive advantage over other fashion retailers by using differentiation competencies in design, information systems, and logistics management. Undoubtedly, in a trend driven market, the speed at which the retailer is able to introduce new products plays a very crucial role.

Another differentiated firm is Apple. Nowadays, in personal computer industry where the product has become a commodity, obviously, it is the low cost player which can deliver the best quality and few defects products at the lowest cost will win the battle. Historically, this should be Dell, Lenovo and HP. However, Apple survives the market because it can provide a uniquely differentiated product in a commodity industry. It has the advantages of brand loyalty, ease of use, and design elegance. Today Apple has been very successful with the iPod, iTune and iPhones.

\subsection{From Resource-based to Capability-based View}

Traditionally, Porter's views focus on an organization's capabilities, core competencies, and competitive advantage. And as a matter of face, those capabilities originate in the resources which the firm possesses. Until now, there are two perspectives in the classical strategic view: A resource-based view and capability-based view. Firstly, a resource-based view believes that firms can provide competitive advantage only when a firm possesses valuable, scarce, inimitable and irreplaceable resources. In other words, the firm's resources must meet three requirements: nontradable, nonimitable, and nonsubstitutable. Secondly, the capability-based view suggests that the success of a firm's strategy is completely dependent on the ability of transforming the resources to competitive advantage. Therefore the capability-based view actually moves a step closer to understanding how enterprises develop and maintain their sources of competitive advantage. (Liqin Ren, Guangya Xie, Koos Krabbendam, 2009)

In terms of inimitable and irreplaceable resources, what has been the source of Intel's competitive advantage in the business of microprocessor for PC? Why has this advantage persisted for so long? What are the barriers to imitation? The reasons are analyzed below:

- Wintel alliance brings great switching costs to competitors. Intel and Microsoft successfully create co-ownership of the industry standard for personal computers. Even if the competitors can make a better microprocessor, it must persuade the industry standard: Windows operating system to run on that microprocessor in order to survive the market.

- Based on Moore's Law, Intel can continually improved the power and lowered the cost of its processors. Intel in fact possesses world class product R\&D knowhow which it was accumulated over time through experience, and which enables it to continue to improve microprocessor performance. Obviously, it knows more than any other 
company in the world about manufacturing microprocessors. With a learning effect, this knowledge help Intel to improves yields over time, boost productivity and lower costs. Much of this knowledge is socially complex tacit knowledge that does not reside in any one individual, but in an entire team of engineers.

- To make sure that no competitor expropriates its $R \& D$ knowhow, Intel has aggressively defended its intellectual property rights, often through preemptive law suits. It means that a signal has been sent to potential competitors - if you try to encroach upon our turf, we will sue you.

- To further keep them at bay, Intel has invested aggressively in brand building strategies at the consumer level. Its Intel Inside campaign raised the company's profile with consumers, and has helped to sustain its advantage.

- Intel also enjoys substantial economies of scale. With the costs of building a new fabrication facility, company needs a guarantee of a large volume to cover their fixed costs and drive down average costs.

In conclusion, these advantages together have persisted for a long time, as a result the barriers to imitation are numerous, including the costs of switching to none Wintel alliance, the brand, the intellectual property, and the accumulated knowhow.. The barriers to imitating these for a denovo competitor are enormous.

\section{Overcoming Business Inertia}

With the development of business development, the traditional core completive thinking (rare, valuable, nonimitable, and nonsubstitutable resources -based view) cannot simply be enough in order to capture sustainable competitive advantages. In the following part, the author will analyze why the temporary competitive advantage built by the initial strategy may disappear quickly in the business world. Lots of Business history suggests that enterprises will fail because the firm finally live in the shadows cast by past successes. The reason is that companies find it difficult to change their strategies and structures in order to adapt to changing competitive conditions. That is to say, an organization's capabilities contribute to inertia because they are difficult to change. Changing capabilities would require a redistribution of power and influence everyone in the organization, and therefore will be resisted. Thus, capabilities can provide competitive advantage and also competitive disadvantage. A well known case is IBM. Historically, during its rise, it had lost its market position because it can no longer search for new opportunities in creating new products. Its main goal became to protect the old product: mainframes and mainframe technology. Then IBM missed opportunities to dominate the other emerging segments of the computer market-minicomputers, personal computers, workstations, and software and services-because of its "mainframe mindset." The IBM case highlights how a company becomes more and more committed to its core competence, then becomes less able to change direction, can not see the dangers from changes in technology and the environment.

\subsection{The Demise of DEC-- The Icarus Paradox}

The Icarus paradox is based on the Greek myth of Icarus, who made himself a pair of wings from wax and feathers and then flew so well that he went too close to the sun, which melted the wings, and he plunged to his death. The paradox suggests that his greatest asset, his ability to fly, gave rise to his demise. Many successful companies become so dazzled by their own early success that they believe that operate in the same way will lead to future success. This attitude, finally leads a company to become so specialized and inner-directed that it loses sight of market realities .Sooner or later failure must ensue. Here a typical example is the DEC Company. By 1990, DEC's superiority in producing high quality VAX minicomputers made it one of the largest corporations in the world. However, the company's success carried the seeds of its destruction. An increasingly narrow focus on engineering capability led to a neglect of other functions, such as marketing, servicing and so on. The firm became dull to the dynamic customer needs and industry conditions. Then DEC went through a terrible change of fortune in the early 1990s, and finally was acquired by Compaq in 1998. (Compaq was acquired by Hewlett Packard in 2001.)

\subsection{The Crisis of Nokia -----Prior Strategic Commitment}

Prior strategic commitments may also contribute to competitive failure because the firms only are good at investments in specialized resources, and these resources are not well suited for other evolving uses. Therefore, changing resources is difficult and expensive. In 2001, when Apple iTunes 1.01 was introduced to provide songs and video files for Apple computer users by downloading them from the internet, it was apparently not clear to Nokia that they should react quickly. Nokia did not apparently see the approaching crisis. Traditionally, Nokia's specialized resources are focused in producing better and cheaper mobile phones. Nokia's principal decision at that time was not changed in the crisis when the Apple iPhone began to dominate high-end smart phone sales. A total of seven critical years passed before Nokia developed a similar site to iTunes. In a crisis, usually the preliminary stage is often difficult to see. This is especially true with respect to dramatic changes in technology. It is not clear if the new technology will actually create a crisis. It is very difficult for Nokia's top-managers to recognize the impending crisis 
in 2001 when Apple introduced iTunes.

Significantly, the corporate culture at Nokia and the morale of employees was very stable as the firm focused on design, manufacturing and sales of mobile phones. These are specialized resources which create the completive advantage for a long time. However, the shift to smart phones that used an internet platform similar to iTunes that would make internet content available was not a good fit with the traditional Nokia corporate culture. In stead, Nokia needed to recognize earlier the importance of hiring the best internet-savvy professionals who could make Nokia a leader in technological innovations, in other words, the smart choice for Nokia is to change the specialized resources, and to invested in new human resources, such as the best and brightest software engineers and researchers to develop successful internet business in order to survive the crisis. (John P. McCray, Juan J. Gonzalez, John R. Darling, 2011)

\section{Building Strategic Resilience}

Apparently, complacency is a seductive companion to success, for business organizations, big, stable companies seem to attract bureaucratic, hierarchical people. Unfortunately, people can see the problem coming, but can't keep them out. Therefore, all companies need to continually exercise their Operational resilience to prepare for setbacks and the maneuvers of rivals. From recovery to renewal, resilience has two dimensions: Operational resilience is the ability to bounce back after a crisis. The other is Strategic resilience is the ability to turn threats into opportunities before it is too late. Preparing for a response to adversity implies the organization should enhance the organizational defenses strategically. To increase their resilience, all companies need to occasionally rehearse their readiness for change. But to achieve the resilience in a dynamic, highly competitive marketplace, it requires a commitment to continual customer-focused agility training. The firm must learn how to turn threats into opportunities and how to identify opportunities earlier than competitors. (Liisa Va“ likangas and A. Geor ges L. Ro mme, 2012)

It is a well-known fact that IBM has ever lost its market competitive advantage because of the Icarus paradox in the earlier years. Fortunately, the company survives again recently. This case focuses on the period after 1993. In that year, CEO John Akers resigned after many years of trying and failing to return the company to profitability and innovation. Outsider Louis Gerstner took over the leadership role and revitalized the firm, shaking up the mainframe culture, focusing on efficiency, and encouraging innovation. Every operation Gerstner took was oriented toward improving customer satisfaction and service. IBM developed an entirely innovative business model, which is not based on the sale of mainframes, computers, or other specific products, on the other hand, the firm's true focus shifted to services, E-business and other technological innovations.By 2006, IBM's performance was recovering as a result of Palmisano's strategic initiatives, in addition, it has shifted toward higher profit-margin services and automating traditional business processes like procurement, finance, and human resources. In particular, its higher profit business transformation outsourcing grew by 45\%. IBM's performance continued to improve through 2007 into 2008 , its profits rose $12 \%$ once again because of its focus on selling higher-margin software and services, also its profit margins steadily improved. Indeed, by 2008 IBM software's revenue showed the biggest gain and had become the largest contributor to IBM's profits. Undoubtedly, IBM has successfully revitalized itself, and showed great resilience ability after long-term falling period. Its story has become the most famous research case for large, bureaucratic, and hierarchical organizations

\section{Organizational Transformation -- The Way to Sustainability}

\subsection{Organizational Transformations (OT)}

As a key response to environmental changes, strategic change is emphasized as a critical antecedent to the survival of firms suffering significant environmental uncertainty. From the perspective of research literature, the adaptation perspectives was a dominant perspective in the Sixties and seventies, and organizational transformation (OT) appeared in the eighties as a response to a new global economic situation. As the environment became more complex, adaptation was not enough, organizations needed to transform themselves. Johan Adam s' Transforming Work was one of the first books to explore the concept of transformational change, quickly followed by several others who further developed the subject. According to these researchers, transformation means not only the strategy and the structure's change but also the culture of the organization. OT can only be effectively operated when most of the staff members can change their behavior, which refers to second-order change (Meyer, Bet tenhause n, \& Tyler, 1993).First -order change is incremental and convergent, second-order change is transformational, radical, and it fundamentally changes the organization (Guido Maes, Geert Van Hootegem,2011).

\subsection{Apple’s Successful Organizational Change}

Obviously, a well-known transformational story is APPLE, Jobs has successfully transformed APPLE from a PC firm to a promising diversified organization, which has great strategic flexibility to innovate in the market. This revolution 
process is certainly full of adventure and difficulties. In the PC industry where the product has become a commodity, it is the low cost player which can deliver the best quality at the lowest cost will win. Historically this has been Dell, Lenovo and HP. However, Apple is protected in the sense that it has a uniquely differentiated product in a commodity industry. It has the advantages of brand loyalty, ease of use, and design elegance. After the early year's failure of marketing PC, Apple has been very successful with the iPod, iTunes and iPhones. In a decade APPLE has gone from a computer manufacture to a world beater in personal music players, mobile phones, music retail, tablet computing, TV hardware manufacture. Especially, the firm has actually dominated the market for mobile phone applications by being open and rewarding developers with generous profit sharing. In 2010 it hosted over 250,000 "apps" from outside developers, and while it is criticized for being "closed" in operating a strict policy in monitoring the content of these apps, it is generating almost $\$ 1$ bn a year through the innovation and has made many developers millionaires.

There are a number of reasons for Apple's successful organizational transformation. Firstly, the iPod itself was technologically sophisticated and cool, the design elegance helped to drive demand. Secondly, iTunes files could only be played on the iPod created a closed world in which copyright violations were less likely to occur. This helped to allay the fears of music publishers regarding illegal file sharing. Last but not the least, Apple offered the music companies a great deal - of the $\$ 0.99$ paid for every download, $\$ 0.89$ reportedly goes straight to the music companies. They capture most of the economic profit. With regards to iPhone, Although the iPhone was not the first smart phone, its market share is growing rapidly. The reason is clear now: Apple has realized the importance of applications for sales of the iPhone, and is creating incentives for third part developers to make and sell applications through its apps store. Essentially, Apple is leveraging a network effect successfully. The more valuable apps offered on the iPhone platform, the greater the utility of owning an iPhone, the greater demand will be created, and the more apps will be offered. Previously, Microsoft utilized such a network effect with Windows, now Apple is trying to utilize it with its iPhone. The successful organizational transformation of Apple's success in the iPhone business depends in large part upon its ability to win what is rapidly becoming a format war in the smart phone business. To do that, it must exploit network effects, and so far Apple seems to be doing a better job than its competitors.

\section{Business Sustainability --- Next Strategy for Organizations}

2010, Accenture and the United Nations Global Compact (UNGC) published A New Era of Sustainability, the world's largest CEO study on sustainability until now. Through conversations with $50 \mathrm{CEOs,} 50$ further board executives, academic experts and civil society leaders, supported by a survey of 766 CEOs from over 100 countries and 25 industries, this study uncovered a picture of corporate sustainability which changed totally from the previous years. Leading CEOs view sustainability as an engine of future growth. As companies turn their sights to new waves of growth, sustainability is a key element in their strategies to grow revenues and broaden their geographic footprints into the emerging markets. Apparently, Today's CEOs across the globe believe that sustainability is beginning to fundamentally reshape the business context .In the coming years, resource scarcity and climate change, as well as the pressing and urgent need for social and economic development, will alter supply, demand and the rules of the game, both in industries traditionally associated with sustainability, such as energy and utilities, and in those such as banking and communications which will play a role in enabling the transition towards a new era of sustainability. There is a growing belief that in the next decade, sustainability issues will be integrated into all elements of business.

For instance, in the area of retail industry, utilitarian values have long dominated in the sector, but a totally different view: hedonic values have been examined more recently. In conceptual terms, utilitarian consumers are perceived as task-related and rational, however hedonic consumers are perceived as emotionally driven. That is to say utilitarian values emphasize economic and functional values; retailers can meet these values through strategies such as lower prices easily in the past decades. But the situation has changed a lot in today's business area. For example, Wal-Mart has been the target of a great deal of negative publicity in the media, and it has recently been trying to neutralize this publicity by giving interviews, producing press releases, and publishing advertisements that emphasize community involvement. In deed, Wal-Mart has built a set of salient positive attributes: Everyday low price, courteous service by store greeters, store layout and renovations, active community involvement, such as youth education. Maybe it's time for our businesses organizations to change the way they operate if they are to succeed and prosper. This is not just about re-educating a few managers, this requires a top-down and bottom-up strategy (Moira Teed, Christopher Norman, May Aung, Doug Adlam, Sameer Goswami, Brae Surgeoner, BiChen Zhu, 2010).

Currently, there has been a significant growth in public awareness and concern around a range of trends and issues like climate change, biodiversity, and availability at natural resources such as energy and water, pressures to improve quality of life, better healthcare, more resilient livelihoods, or freedom from violence, improved respect for human rights, better governance and the elimination of corruption. Moreover, during the 1990s and 2000s, more and more 
people have come to share the view that business organizations should play a pivotal role in these interconnected issues and trends. These shifts in public opinion have combined to present a range of strategic drivers for change in organizations. As a result, over the past two decades, a growing number of organizations have begun to respond strategically to pressures and opportunities around these trends and issues, with more and more innovation in management processes, products and services, business models and partnerships. Such activities are frequently referred to as corporate citizenship, sustainability and shared value. This growing recognition of the need to develop a different mindset and a wider range of skills has led to a new era of business operations. (Prahalad, 2009; Lubin and Esty, 2010; Porter and Kramer, 2011).

\section{Conclusion}

The past two decades have seen an obvious shift in the nature of the relationship between business organization and society, with business organizations increasingly playing a more proactive role in wider societal issues. Apparently, in today's turbulent business world, innovation must be a consistent and continual process. Enduring success requires sustainable competitive advantages and implies continuous improvement and innovation (Han et al., 1998; Lewis, 1993).For firm, business strategy becomes the means to create competitive advantage faster than rival's mimicking your current advantages. Indeed, the strategic management has transferred to an innovation-based source of competitive advantage. That is to say, strategic flexibility, which reflects the capabilities of a firm to reallocate and reconfigure its organizational resources, plays a key role for the organizations. In the twenty-first century, strategic leaders must frequently contend with the complexity and uncertainty of organizational change (Lawler and Worley, 2006). One of the most difficult aspects of leading organizational change is the leader's ability to diagnose and develop the organization's capacity for change. This paper is empirically explored in many explorative, historical case studies to research the evolution path of firm's strategic planning processes. The author aims at helping the firm leaders to solve complicated, uncertain management issues arising from today's dynamic business areas. However, the limitation of its contribution is that this paper does not follow a standard research approach (empirical modeling), but builds on insights from existing literatures. Information and data were collected from the media and other database sources. As a result, more detailed work should be carried on in the future research.

\section{References}

Andrew Cameron. (2011). A sustainable workplace - we're all in it together. Strategic Direction, 28(1), 3-5. http://dx.doi.org/10.1108/02580541211188987

Christopher Heywood, \& Russell Kenley. (2008). The sustainable competitive advantage model for corporate real estate. Journal of Corporate Real Estate, 10(2), 85-109. http://dx.doi.org/10.1108/14630010810905606

Gayle C. Avery, \& Harald Bergsteiner. (2011). How BMW successfully practices sustainable leadership principles. Strategy \& Leadership, 39(6), 11-18. http://dx.doi.org/10.1108/10878571111176583

Guido Maes, \& Geert Van Hootegem. (2011). Toward a Dynamic Description of the Attributes of Organizational Change. In Abraham B. (Rami) Shani, Richard W. Woodman, \& William A. Pasmore (Eds.), Research in Organizational Change and Development (Vol. 19, pp. 191-231). Emerald Group Publishing Limited. http://dx.doi.org/10.1108/S0897-3016(2011)0000019009

John P. McCray, Juan J. Gonzalez, \& John R. Darling. (2011). Crisis management in smart phones: the case of Nokia vs Apple. European Business Review, 23(3), 240-255. http://dx.doi.org/10.1108/09555341111130236

Liisa Välikangas, A., \& Georges L. Romme. (2012). Building resilience capabilities at "Big Brown Box, Inc.". Strategy \& Leadership, 40(4), 43-45. http://dx.doi.org/10.1108/10878571211242948

Liqin Ren, Guangya Xie, \& Koos Krabbendam. (2009). Sustainable competitive advantage and marketing innovation within firms: A pragmatic approach for Chinese firms. Management Research Review, 33(1), 79-89. http://dx.doi.org/10.1108/01409171011011580

Matthew Gitsham. (2012). Experiential learning for leadership and sustainability at IBM and HSBC. Journal of Management Development, 31(3), 298-307. http://dx.doi.org/10.1108/02621711211208925

Moira Teed, Christopher Norman, May Aung, Doug Adlam, Sameer Goswami, Brae Surgeoner, \& BiChen Zhu. (2010). Wal-Mart is coming to Guelph: hedonic to utilitarian shoppers' perceptions. Qualitative Market Research: An International Journal, 13(2), 130-153. http://dx.doi.org/10.1108/13522751011032584

Petri Ahokangas, Anita Juho, \& Lauri Haapanen. (2010). Toward the theory of temporary competitive advantage in internationalization. In Ron Sanchez, Aimé Heene (Eds.), Enhancing Competences for Competitive Advantage, Advances in Applied Business Strategy (Vol. 12, pp. 121-144). Emerald Group Publishing Limited. 
http://dx.doi.org/10.1108/S0749-6826(2010)0000012008

Reut Livne-Tarandach, \& Jean M. Bartunek. (2009). A new horizon for organizational change and development scholarship: Connecting planned and emergent change. In Richard W. Woodman, William A. Pasmore, Abraham B. (Rami) Shani (Eds.), Research in Organizational Change and Development (Vol. 17, pp. 1-35). Emerald Group Publishing Limited. http://dx.doi.org/10.1108/S0897-3016(2009)0000017003

William Judge, \& Thomas Douglas. (2009). Organizational change capacity: the systematic development of a scale. Journal of Organizational Change Management, 22(6), 635-649. http://dx.doi.org/10.1108/09534810910997041

Yuan Li, Zhongfeng Su, Yi Liu, \& Mingfang Li. (2011). Fast adaptation, strategic flexibility and entrepreneurial roles. Chinese Management Studies, 5(3), 256-271. http://dx.doi.org/10.1108/17506141111163354 